\title{
JCAPS
}

\section{TEACHING STUDENT LEADERSHIP, ETHICS, AND GROUP RESPONSIBILITY FOR HAZING PREVENTION: AN EXPLORATORY STUDY}

\author{
Stacey Malaret, University of Central Florida \\ Elizabeth Allan, University of Maine \\ Germayne Graham, University of Central Florida \\ Corey Esquenazi, University of Central Florida \\ Desia Bacon, University of Wisconsin-Madison \\ Paul Whalen, Pennsylvania State University
}

Hazing is generally defined as any activity expected of someone joining or participating in a group that humiliates, degrades, abuses, or endangers them regardless of a person's willingness to participate (Hoover, 1999) and has been documented among college students in groups ranging from athletics to marching bands to fraternities and sororities (Allen \& Madden, 2008). This investigation examined attitudes and perceptions about hazing for students in a leadership development program compared to their peers. Both groups participated in an online hazing prevention education module and completed pre-and post-surveys. Data were analyzed using statistical two-tailed t-tests for analysis. Though the literature on hazing is highly suggestive of linkages between leadership development and hazing mitigation, it appears this may not be the case. Findings from this investigation revealed that leadership students at this institution responded less strongly against hazing when compared with their peers in the general student body.

HAZING TRAGEDIES MAKING NATIONAL HEADLINES has sharpened public attention and campus commitment to finding effective strategies for preventing the hazing and harm resulting. Hazing, generally defined as "any activity expected of someone joining or participating in a group that humiliates, degrades, abuses, or endangers them regardless of a person's willingness to participate," is a campus safety issue and behavior that runs counter to the missions of postsecondary institutions (Allan \& Madden, 2008, p. 2). News reports, anecdotal data, and research reports indicated that hazing could include beating, paddling, whipping, and striking; blood pinning; branding, tattooing, cigarette burning, and burning; excessive calisthenics; confinement to restricted areas; consumption of nonfood substances; circumstances leading to drowning and near-drowning; blunt trauma from falls after having to climb roofs, ledges, and bridges; immersion in noxious substances; psychological abuse; and sexual assaults (Finkel, 2002). Furthermore, hazing can also be lethal (Nuwer, 2018).

Hazing on college campuses appears relatively widespread, with one national study that has reported that 55\% of undergraduate students belonging to clubs, organizations, and teams, experiencing it (Allan \& Madden, 2008; 2012). More recently, Allan, Kerschner, and Payne (2018) found that $26 \%$ of students enrolled at institutions participating in the Hazing Prevention Consortium experienced hazing. In addition to the individual harm that may occur, hazing can breed mistrust among groups, contribute to unsafe campus environments, and diminish human and other campus resources in the wake of an incident. Despite the gravity of consequences, peer-reviewed research about hazing and its prevention is in nascent stages of development. Moreover, given that clubs, teams, or other types of student organizations are leadership laboratories for college students, hazing can be described as a leadership concern with implications for student moral and ethical development and civic engagement. As such, understanding hazing is a vital issue for leadership educators, student activities professionals, and student 
leaders, and the field of leadership education may provide fruitful ground for research that explores hazing and its prevention. In this paper, the researchers detailed a study designed to examine relationships between ethical leadership development and hazing attitudes of student participants following exposure to the Social Change Model of Leadership (SCM) in an undergraduate leadership development program.

\section{RELEVANT LITERATURE}

The body of literature about college hazing included several national studies, multi-campus (e.g., Allan \& Madden, 2008; 2012; Allan, Kerschner, \& Payne, 2018), and single-campus studies drawing from several different data sources, including surveys and qualitative data from interviews and focus groups (e.g., Campo, Paulos, \& Sipple, 2005; Owen, Burke, \& Vichesky, 2008). Basic descriptive questions about the nature and extent of hazing provided a foundation for more in-depth exploratory and experimental designs and evaluation studies of hazing prevention initiatives. As the field continues to evolve, an increasing number of researchers have focused on examining hazing within particular group contexts, e.g., athletics, fraternities, sororities, and marching bands (e.g., Hoover, 1999; Johnson \& Holman, 2004; Silveira \& Hudson, 2015).

Media reports and researchers have reported a wide range of hazing behaviors, including activities that cause physical and psychological harm, involve high-risk substance abuse, and sexual violence (Finkel, 2002; Finley \& Finley, 2007; Flanagan, 2017; Hoover \& Pollard, 1999; Kirby \& Wintrup, 2002). Further, with increasing recognition of how socio-cultural forces and identity may shape hazing experiences and perceptions of it, researchers have also explored questions related to gender, race, and sexuality in relation to hazing (e.g., Allan \& Kinney, 2018; Jones, 2004; Parks \& Laybourn, 2017; Parks et al., 2015; Rogers et al., 2012; Veliz-Calderon \& Allan, 2017).

Despite the risks, some students continue to engage in hazing practices. Some researchers contended that hazing's persistence is attributable primarily to perceived positive outcomes such as maintaining group hierarchy and cultivating group or team commitment (Campo et al., 2005; Cimino, 2011; Kirby \& Wintrup, 2002; Keating et al., 2005). However, not all investigations have produced results in alignment with such conclusions. Some studies have found that hazing diminishes group cohesion and undermines relationships between teammates and peers (e.g., Johnson, 2011; Van Raalte, Cornelius, Linder, \& Brewer, 2007).

Two national investigations reported that nearly half (47-48\%) of students arrive at campus having experienced hazing in high school (Allan \& Madden, 2008; Hoover \& Pollard, 2000). Some posited that these prior experiences with hazing might contribute to the normalization of hazing in college settings (Allan \& Madden, 2012; Allan, Payne, \& Kerschner, 2015). Research has also demonstrated a lack of correlation between hazing student experiences and their willingness to label those experiences as hazing (Allan \& Madden, 2008; Allan, Kerschner, \& Payne, 2018). Campo et al. (2005) indicated that a possible explanation for the reported gap between the experience of hazing and self-reports of hazing is that students ascribe to a narrow definition of hazing that emphasizes extreme forms, including being tied up, beaten, or raped.

\section{Hazing and Ethical Group Behavior}

The concept of hazing corrupting and negatively influencing group behavior was described by Allan and DeAngelis (2004), who stated that "hazing is about abuse of power and control over others" (p. 76). Cimino (2011) identified this perversion of group dynamics in slightly different terms when they described hazing "as the generation of induction costs (i.e., part of the experiences necessary to be acknowledged as a 'legitimate' group member) that appear not attributable to group-relevant assessments, preparations, or chance" (p. 242).

Hazing can also be conceptualized as the inverse of collaboration. Komives and Wagner (2009) defined collaboration as "the need for shared responsibility, authority, and accountability, and the benefit of having multiple perspectives and talents in a group process" (p. 195). These over conformity, social control, and induction costs were reflective of Nuwer's analysis that suggests students experience a willingness to endure discomfort and abuse due to the 'ritual' aspect in shared hazing experiences that are for the perceived good of the group (1999). "Hazing demonstrates a group's power and status; it teaches precedence as a way to subjugate the individual for the perceived good of the group" (Nuwer, 1999, p.39). 
Pascarella and Terenzini (2005) noted the tie between moral and cognitive development and identified that a more advanced intellect would likely result in a higher developed moral reasoning. This is backed up by King and Mayhew's (2002) research on pro-social behavior, which indicated that the collegiate experience strengthens an individual's moral judgment. The authors stated that this is due to individuals gaining higher intellect as they further matriculated through their undergraduate careers. The authors suggested that moral reasoning and judgment both increased throughout the college years, and the college environment provided multiple opportunities to do so.

\section{Leadership and Bullying}

Although there is little research connecting Leadership with hazing prevention, an adjacent field of study may provide a framework for comparison. Literature on workplace bullying suggested that an essential antecedent to the perception and perpetration of bullying was managers' leadership style (Samnani \& Singh, 2012). "Bullying is an escalated process in the course of which the person confronted ends up in an inferior position and becomes the target of systematic negative social acts" (Einarsen, Hoel, Zapf, \& Cooper, 2003, p. 15). These forms of interpersonal violence shared some typical dynamics with hazing, as hazing can also be an escalated process that continues to become more dangerous, and hostile social acts are often the result of hazing. Workplace bullying was not necessarily related to membership in a group or organization, though. A study on leadership styles as predictors of self-reported and observed bullying in the workplace found that bullying correlated with all leadership styles measured (Hoel, Glaso, Hetland, Cooper, \& Einarsen, 2010).

Furthermore, this study found that observers were more likely to associate autocratic leaders with bullying, while those who had been victims of bullying associated non-contingent punishment with perceived bullying (Hoel, Glaso, Hetland, Cooper, \& Einarsen, 2010). Particularly important to the current research, ethical Leadership (Stouten, et al., 2010) and authentic Leadership (Spence Laschinger, Wong, \& Grau, 2012) mediated the perception and perpetration of bullying in the workplace. These findings provided a foundation for considering ethical leadership training and as an approach to hazing prevention.

\section{Hazing Prevention}

The body of literature focused on hazing prevention is still developing. Massey \& Massey (2017) stated, the body of research on hazing in higher education began to develop in the early 1990s with Nuwer's (1990) account of a death from hazing in Greek-letter organization and was bolstered by Shaw's (1992) dissertation discussing hazing practices in sororities (p. 47). Published studies include evaluation studies (Hakkola, Allan, \& Kerschner, 2019; Santacrose, Laurita, \& Marchell, 2019), a data-driven hazing prevention framework to guide practice (Allan, Kerschner, and Payne, 2018), and a campus-level study of change following a comprehensive hazing prevention effort (Marchell, Santacrose, Laurita, \& Allan, forthcoming). Another study by Massey and Massey (2017) focused on a university that did not have a Fraternity and Sorority Life system on campus to ascertain the level of hazing on these types of campuses. It was suggested that hazing still happens in the absence of fraternities and sororities in campus activities. The authors "suggest that efforts to address hazing on college and university campuses need to be targeted more generally to all students to change campus culture rather than designing policies and interventions that target only Greek organizations, athletic teams, marching bands, and other distinct student groups" (p. 60).

While few published studies document the efficacy of hazing prevention, research in related areas of college student health and well-being pointed to the value of public health frameworks for informing hazing prevention. A public health approach emphasized activities that prevent the behavior before it begins (primary prevention). Other forms of prevention were also important, including intervention (secondary prevention) and response (tertiary prevention). Studies from community health affirmed that primary prevention was needed to make significant gains in changing behaviors and shifting cultural norms (Nation et al., 2003). Still, campus professionals often reported spending more time responding to incidents than planning and implementing primary prevention. 


\section{Conceptual Framing}

In 1993, ten leadership specialists, collectively known as the "ensemble," met to create a leadership development model for college students. Funded by a grant from the federal Eisenhower Leadership Development Program, the group developed the Social Change Model (SCM) of Leadership (Higher Education Research Institute, 1996). A fundamental assumption of the SCM was that Leadership is collaborative and effective if based on a collection of actions, shared power, and a social justice commitment. Accordingly, Leadership was also meant to be a group effort, not only the actions of individuals with authority. The model also suggested that values-based Leadership was essential, and thus, it was important for actions to align with the group's values (Higher Education Research Institute, 1996). The model noted that change is necessary for Leadership, and effective leaders could create positive change for a community and its members (Higher Education Research Institute, 1996).

The ensemble developed seven key concepts of Leadership, known as the Seven Cs of the SCM, and was grouped into three areas: individual, group, and societal values noted in Figure 1 (Higher Education Research Institute, 1996). The leadership program studied in this research is modeled after the SCM, and all leadership classes teach the importance of the model and ways that students can embody the model in their lives. The Student Affairs division at University A also has adopted the SCM as the divisional leadership philosophy.

Figure 1. The Seven C's

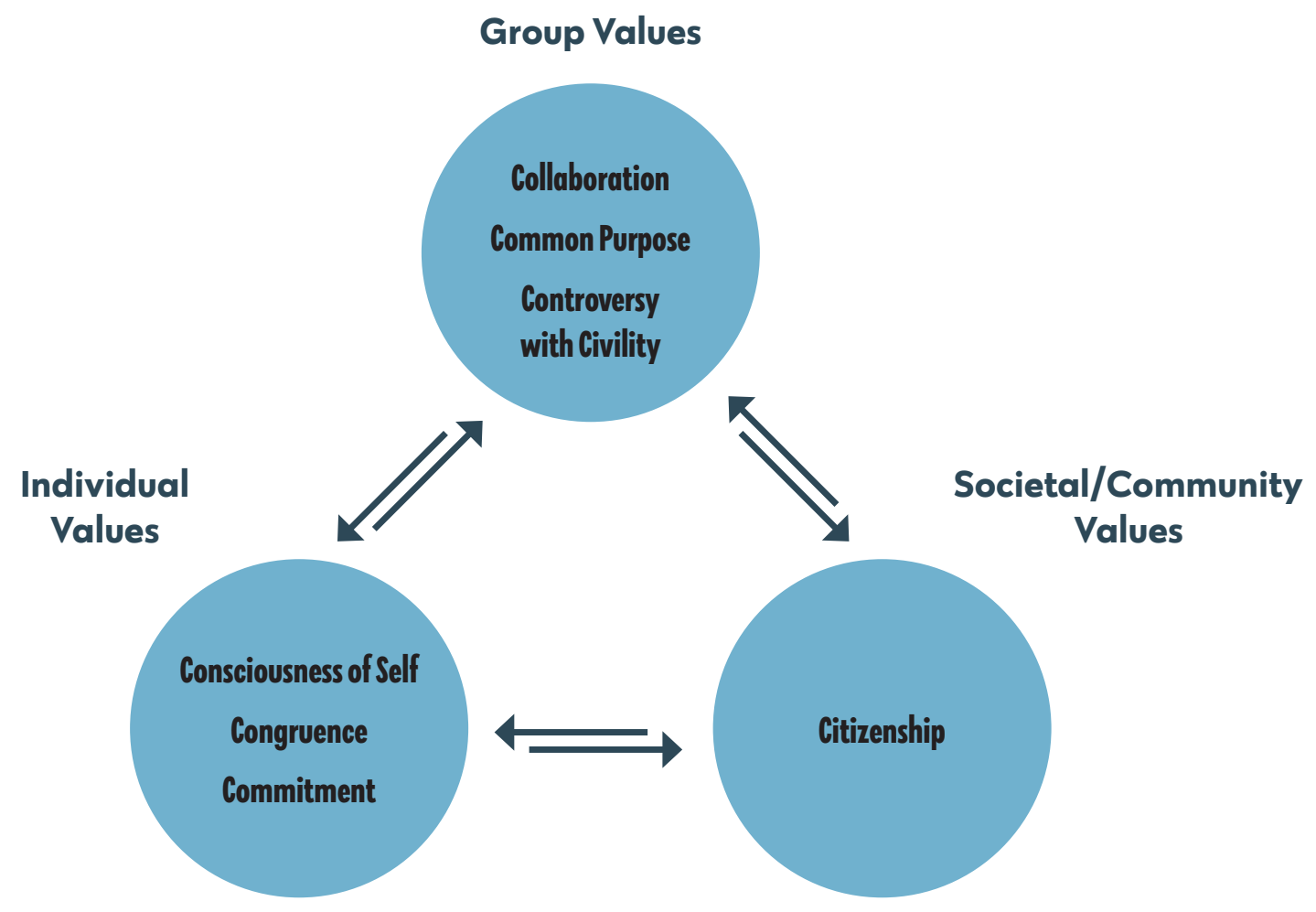

\section{Moral and Ethical Development}

In the six stages of moral development, according to Kohlberg (1976), individuals progress from heteronomous morality, where individuals justify actions based on avoidance of punishment to morality based on principles that benefit all and may or may not be lawful. Kohlberg's Theory of Moral Development analyzes moral reasoning through a series of levels and stages (Evans, Forney, Guido, Patton, \& Renn, 2009).

The post-conventional level spans over the teenage years into adulthood and includes two stages: social contract and principled conscience (Evans, et al., 2009). The social contract is the stage typical in teenage years and describes social mutuality and reciprocity (Evans, et al., 2009). Principled conscience is the final stage, developed 
through adulthood when morality is based on principles that transcend mutual benefit (Evans, et al., 2009). Since most students are transitioning through the post-conventional level during their two years in the FTIC program, the researchers drew on this level as a lens to analyze hazing and how that influences students' willingness to report hazing behaviors (Evans, et al., 2009).

Rationalization of hazing, in terms of building group unity or some other perceived positive characteristic, was seen throughout the literature on hazing as the predominant rationale for its use in a group setting. A sense of belonging was defined as the "psychological sense that one is a valued member of the college community" (Hausmann, Schofield, \& Woods, 2007, p. 804), and community was a sensation that group members have a sense of community and are essential to one another. This group also had a common allegiance or "a feeling that members have of belonging, a feeling that members matter to one another and to the group, and a shared faith that members' needs will be met through their commitment to be together" (McMillan \& Chavis, 1986, p. 9).

According to Bandura (1991), to cultivate this new sense of group identity, individuals were likely to succumb to moral disengagement. As part of Bandura's Social Learning Theory, moral disengagement was described as a person dissociating themselves from their own ethical standards in a given context (Bandura, 1991). These ethical standards were developed over time, and the utilization of these standards can be influenced by environmental factors, such as socialization interactions (Bandura, 1991). Action based on moral judgment can be impeded by peer pressure, or the idea that people will go against their morals or act irrationally to cultivate harmony and consensus. According to Bandura's moral disengagement theory, individuals were unlikely to participate in group-think, or the immoral activities that come with it, unless they felt that acting against their morals could be justified for the good of a purpose bigger than themselves (Bandura, 1999). Moral disengagement theory may explain why students participate in hazing despite the possibility of traumatic experiences for some and even death for others.

\section{Background and Context}

A large public research university (identified here as "University A") was the site for this investigation catalyzed by findings from a campus hazing culture site assessment and a student survey with a random sample of 12,000 students, approximately $17 \%$ of the student population. One finding from the survey was that $20.7 \%$ of the students indicated they had experienced behavior meeting the definition of hazing, yet only $0.7 \%$ of those identified the behaviors (University A: Hazing Survey Report, November 2017).

To address the deficient education about hazing in the state where University A was located, legislators provided funding to create a universal online educational module for all enrolled students. A customized module, purchased from a private company, included university branding. The course was designed to promote awareness, prevention, and reporting of hazing. University A launched the module as one of four required educational components for all newly enrolled students. Pre and post assessments were administered to measure student knowledge of hazing behaviors, likelihood to participate in hazing, and willingness to intervene in a hazing situation.

The leadership development program at University A was created in 1995 as an academic and co-curricular program for incoming first time in college (FTIC) students. The motto of the program, "To Learn, To LEAD, and To Serve," was exemplified by these students' academic rigor, their capacity for Leadership, and their passion for serving the community as social change agents. The academic program consisted of four two-credit hour classes over students' first and second years of study. Students in the FTIC program also had the opportunity to reside in a living-learning community, join student organizations sponsored through the FTIC program, and pursue a minor in Leadership Studies (Leadership development program, n.d.).

The leadership development program studied was a selective academic leadership development program for students committed to academic excellence and making a difference in the world around them. Interested students apply for the program during their senior year in high school after admission to University A. Student leaders in the program guided and led their peers in various ways on campus, including thousands of hours of community service each year. It was the expectation that students chosen for this program become social change agents and leaders with integrity for the university, especially after taking four credited courses based on the Social Change 
Model of Leadership. These emerging leaders were also provided service-learning, co-curricular leadership opportunities, and high impact practices in order to become stronger leaders for the university community. The motto, "To Learn, to LEAD, and To Serve," further showcased the intended caliber of students who entered the program in relation to their academic, leadership, and community skills (Leadership development program, n.d.).

Historically, students in the leadership development program were retained and graduated at a higher rate than students not enrolled in the program. The 2017 entering class was retained at the $97 \%$ level, and the six-year graduation rate was $83.9 \%$ that same year compared with $89.6 \%$ retention and $70 \%$, six-year graduation rate of peers not participating in the program (UNIVERSITY A Collective Impact Strategic Plan, 2016). The 2017 entering class included $21.9 \%$ who were Pell Eligible, $12.9 \%$ who identified as first-generation college students, and $51.3 \%$ of the population identified as an ethnic minority. The leadership program offered several high-impact practices, including small class sizes, communal building spaces, service learning, and shared housing opportunities to encourage campus engagement and student success. These students also participated in the studied hazing prevention module as part of their class curriculum in leadership studies.

\section{Hazing as a Distortion}

As noted, one fundamental assumption of the SCM is that Leadership was a group effort, and this understanding is reflected in the values of the $7 \mathrm{Cs}$ of social change (see Figures 3 and 4). In the leadership development FTIC program, students engaged in leadership development through the SCM and learned ethical values for group dynamics and behavior in four leadership studies classes. The same ethical principles students used in group participation through the SCM were the same ethical values manipulated or transformed through the coercive influences exerted through hazing in group culture.

The consulting team's assessment of the student culture on campus at the university revealed themes that were relatively consistent and reflective of themes in the literature (University A: Hazing Survey Report, November 2014; University of Pittsburgh at Bradford Student Code of Conduct, 2016; Hausmann, Schofield, \& Woods, 2007). More specifically, that hazing is a "non-issue," and students did not feel like they have the power to intervene in hazing situations (University A: Hazing Survey Report, November 2014).

Understanding how hazing characteristics represented a perversion of group dynamics also highlighted the contrast compared to the SCM. In this sense, a hybrid leadership program like the leadership development program studied for this investigation was well-positioned to support more targeted and effective hazing prevention strategies and acculturate students in a community of supportive and positive group dynamics.

\section{Study Design \& Methods}

Given this conceptual backdrop, previous research, and access to relevant data, this study was designed to examine the relationships between leadership development and hazing attitudes, perceptions, and behaviors of student participants following exposure to the SCM of Leadership in an undergraduate leadership development program. In light of the literature on hazing prevention and student leadership development, the leadership development program's initial analysis led a sub-group of the research team to hypothesize a correlation between qualities reinforced through the leadership development program and qualities associated with the prevention reporting of hazing behaviors. The authors hypothesized that leadership development students would have a stronger ethical development level due to their leadership development training. It was further hypothesized that leadership students would be more likely to act on their ethical judgment in reporting hazing incidents and not participating in hazing-related activities.

As previously stated, the original hypothesis resulting from those experiences and review of the literature was that leadership development students, due to their exposure to the SCM, and especially the particulars of the program, should be significantly less likely to participate in hazing behaviors when compared with peers who were not participating in the leadership development program. Other data comparing the two populations seemed to corroborate this initial hypothesis. Consider the following data on retention and six-year graduation rates between leadership development students and the university's FTIC populations: students in the leadership 
development program were consistently retained and engaged in the culture and life of the university, and subsequently graduated, at significantly higher rates than the average university FTIC student population. The SRLS questions 9, 40, and 47 previously discussed provided further, specific evidence of the strength of the SCM as a basis for leadership development.

\section{Sample and Data Collection}

A web-based self-paced hazing education and prevention module that included a pre- and post-assessment were administered. All leadership development students were required to participate in the module for a course grade in their first- or second-year Leadership Studies class $(\mathrm{n}=492)$. All other participants $(\mathrm{n}=12,857)$ accessed the survey from their university portal, as it was a requirement for new students. The leadership development students' responses were noted on the SCM variables from the SRLS, discussed previously, as well as their responses to hazing attitudes and behaviors via the online course module, Hazing Prevention 101: It's Everyone's Responsibility. In the module, the questions utilized a 1 (completely disagree) to 5 (completely agree) Likert scale, specifically:

- The student's likelihood to being inclined to prevent the occurrence of hazing.

- The student's likelihood to being inclined to report the occurrence of hazing.

- Several other questions provide further context and discussion:

- Were you hazed? (No, Yes. the first time was in college, high school, middle school, elementary school)

- Have you participated in the hazing of others?

- I think hazing is unacceptable under any circumstance.

\section{Analysis}

Hazing prevention module pre- and post-data were disaggregated according to the dates respondents completed the module within each three-month quarter time period. When the module was first published, only students in the leadership development program were provided links to complete the module during Q1 of the 2015-2016 year. Following the first quarter, all university students were able to complete the module. Data were separated between Q1 and subsequent module respondents in order to differentiate between students in the leadership development program and all other students in two-tailed t-tests.

\section{RESULTS}

Collected responses from the module in the first quarter (Q1) of 2015-2016 (figure 2) from students in the leadership development program and the general population of university students in the second quarter (Q2-6) of 2015-2016 (figure 3) were compared. Leadership students were represented in Q1, while the other quarters included the general university population. In responding to whether they were inclined to report hazing, a response of 4 or 5 (agree or completely agree) was compared with the total number of responses (1-5) to determine the percent of students willing to report. As noted in the visuals (Figures 4 and 5), 79.0\% (389/492) of leadership development students indicated they would be inclined to report hazing compared with $82.6 \%(10,616 / 12,857)$ of general university students. A two-tailed t-test was used to compare the two different groups. The difference between them was significant at the .045 level (agree or completely agree).

Table 1: Incline to report hazing analysis-Leadership students vs. University students.

\begin{tabular}{|l|l|l|}
\hline \multicolumn{3}{|l|}{ Inclined to report (Agree (4) and Strongly Agree (5)) } \\
\hline & Leadership Program & All university \\
\hline $\mathrm{n}$ & 389 & 10,616 \\
\hline $\mathrm{N}$ & 492 & 12857 \\
\hline$\%$ & 0.7907 & 0.8257 \\
\hline $\begin{array}{l}\text { \% difference: }-0.035 ; \mathrm{z}=-2.005 \\
\text { One-tail: } 0.0225 ; \text { Two-tail:0.045 }\end{array}$ \\
\hline
\end{tabular}




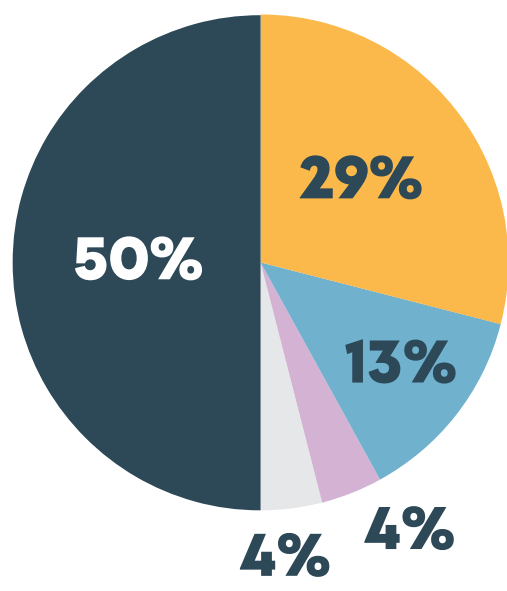

\begin{tabular}{l|l}
$4 \%$ & Inclined to Report 1 (totally disagree) \\
\hline $4 \%$ & Inclined to Report 2 \\
\hline $13 \%$ & Inclined to Report 3 \\
$29 \%$ & Inclined to Report 4 \\
\hline $50 \%$ & Inclined to Report 5 (completely agree)
\end{tabular}

Figure 3: University student responses (Q2 2015-Q6 2016).

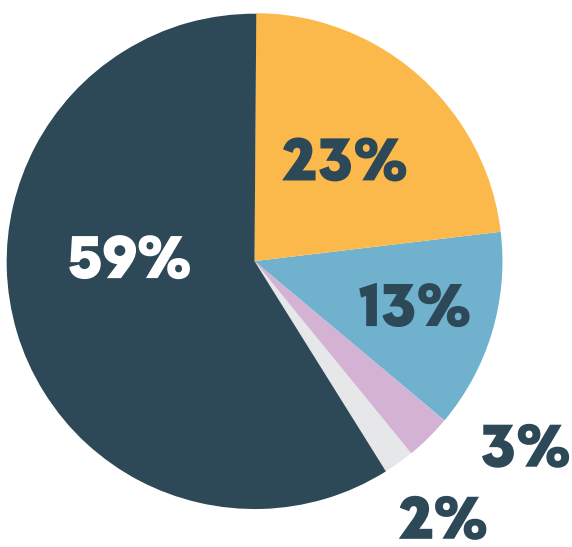

\begin{tabular}{|c|c|}
\hline $3 \%$ & Inclined to Report 1 (totally disagree) \\
\hline $2 \%$ & Inclined to Report 2 \\
\hline $13 \%$ & Inclined to Report 3 \\
\hline $23 \%$ & Inclined to Report 4 \\
\hline $59 \%$ & Inclined to Report 5 (complete \\
\hline
\end{tabular}

When responding to whether they were inclined to act to prevent hazing, a response of 4 to 5 (agree or completely agree) was again compared with the total number of responses (1-5) in Figures 10 and 11. Similarly, 70.9\% (349/492) of leadership development students were willing to prevent hazing compared to $80.2 \%(10,313 / 12,857)$ of university students. A two-tailed t-test was used to compare the two different population sizes. The difference between the two groups proved significant at the $<.0002$ level (agree or completely agree).

Table 2: Inclined to prevent hazing analysis-Leadership students vs. University students.

\begin{tabular}{|l|l|l|}
\hline \multicolumn{3}{|l|}{ Inclined to prevent (Agree (4) and Strongly Agree (5)) } \\
\hline & Leadership Program & All university \\
\hline $\mathrm{n}$ & 349 & 10,313 \\
\hline $\mathrm{N}$ & 492 & 12857 \\
\hline$\%$ & 0.7093 & 0.8021 \\
\hline $\begin{array}{l}\text { \% difference: }-0.0928 ; \mathrm{z}=-5.037 \\
\text { One-tail:<.0001;Two-tail: }>.0002\end{array}$ \\
\hline
\end{tabular}




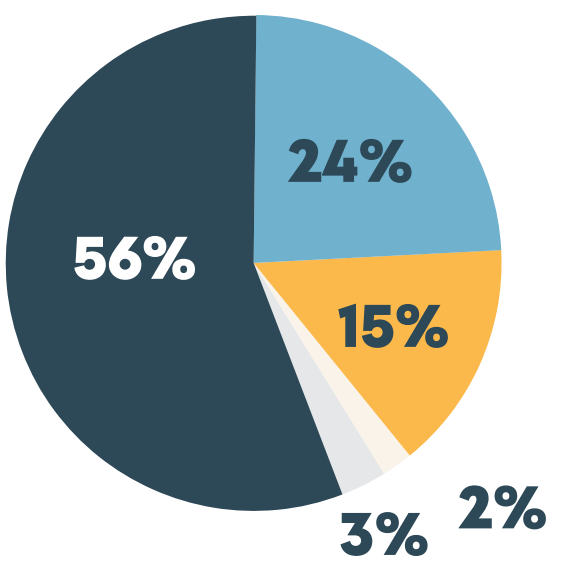

\begin{tabular}{l|l}
\hline $3 \%$ & Inclined to Prevent 1 (totally disagree) \\
\hline $2 \%$ & Inclined to Prevent 2 \\
\hline $15 \%$ & Inclined to Prevent 3 \\
\hline $24 \%$ & Inclined to Prevent 4 \\
\hline $56 \%$ & Inclined to Prevent 5 (completely agree)
\end{tabular}

Figure 5: University student responses (Q2 2015-Q6 2016).

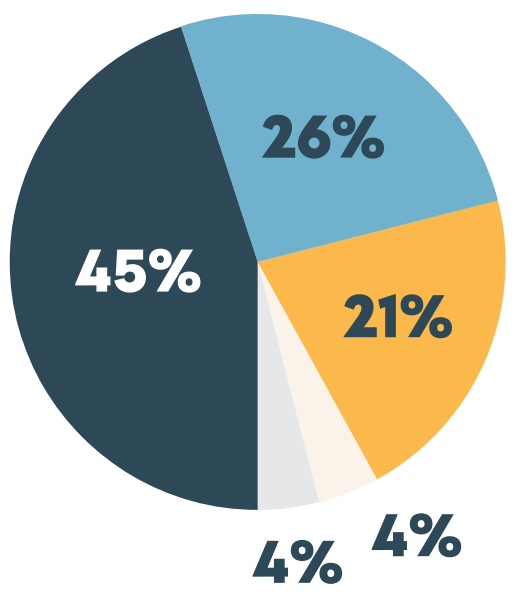

\begin{tabular}{|c|c|}
\hline$\%$ & Inclined to Prevent 1 (totally disagree) \\
\hline $4 \%$ & Inclined to Prevent 2 \\
\hline $21 \%$ & Inclined to Prevent 3 \\
\hline $5 \%$ & Inclined to Prevent 4 \\
\hline & Inclined to Prevent 5 (completel \\
\hline
\end{tabular}

In contrast to our hypotheses, the results of this investigation indicated that leadership development students were significantly less likely to report hazing and act to prevent it. Also of interest were the findings relative to who had been hazed and who had participated in hazing others.

Table 3: Response to if students have previously been hazed or hazed others.

\begin{tabular}{|l|l|l|}
\hline & $\begin{array}{l}\text { Leadership Development } \\
\text { Students }\end{array}$ & University Students \\
\hline $\begin{array}{l}\text { Yes } \\
\text { (respondents } \\
\text { admitted to } \\
\text { previously being } \\
\text { hazed) }\end{array}$ & $11.4 \%(57 / 497)$ & $9.2 \%(1235 / 13,434)$ \\
\hline $\begin{array}{l}\text { No } \\
\text { (respondents } \\
\text { denied in having } \\
\text { hazed others) }\end{array}$ & $93.34 \%(464 / 497)$ & $95.54 \%(12,835 / 13,434)$ \\
\hline
\end{tabular}

Hence, $11.4 \%$ of leadership development students have previously hazed, while only $9.2 \%$ of the general university population has previously hazed others. 
One potential explanation for the results relative to prevention and reporting is that leadership development students have been subjected to or involved in hazing at greater rates than other students. Research on hazing has repeatedly demonstrated that most students did not believe there is a problem with hazing, and some even believed that hazing was a positive experience (Allan \& Madden, 2008). Students who have been hazed were significantly more likely to perpetuate hazing, thus the higher proportion of leadership development students who reported they have both been hazed and participated in hazing conformed with the other data. Similarly, when asked whether they believe hazing was unacceptable, the number of students responding to perceiving hazing as 'unacceptable' conformed to the discussion thus far.

Table 4: Pretest and post-test results asking if hazing is acceptable.

\begin{tabular}{|l|l|l|}
\hline & $\begin{array}{l}\text { Leadership Development } \\
\text { Students }\end{array}$ & University Students \\
\hline $\begin{array}{l}\text { Is hazing } \\
\text { unacceptable? } \\
\begin{array}{l}\text { Initial Survey } \\
\text { (pretest) }\end{array}\end{array}$ & $50.5 \%(251 / 497)$ & $47.24 \%(6,776 / 14,343)$ \\
\hline $\begin{array}{l}\text { Is hazing } \\
\text { unacceptable? Final } \\
\text { Survey (post test) }\end{array}$ & $73.8 \%(363 / 492)$ & $75.2 \%(10,098 / 13,434)$ \\
\hline
\end{tabular}

Of note was a $27.96 \%$ increase from pre to post for general university students relative to the belief that hazing was unacceptable. By contrast, the change from pre to post-test for this variable was $23.3 \%$ for leadership development students, with a post-test percentage lower than the general university population. This was consistent with the data found in the hazing prevention course survey report, prepared by the Center for Digital Education (2018). Student intolerance of hazing increased by $18 \%$ from pre to post-test after reviewing the hazing prevention module $(n=90,016)$. The author was unsure if there was confounding variation in the findings due to the time difference of data collection for both groups.

\section{DISCUSSION}

Leadership in student organizations in college may mirror hierarchical leadership models in the workplace. The literature on workplace bullying indicated that more democratic modes of Leadership may have a mitigating effect on the perception of abusive work environments (Hoel, Glaso, Hetland, Cooper, \& Einarsen, 2010). Yet, in this research study, an explicitly democratic approach to leadership development with college students, the leadership curriculum based on the SCM, did not appear to mitigate attitudes and behaviors associated with hazing, a type of abuse in a group context. Rather, the results from this investigation indicated that students involved in the leadership development course grounded in the SCM were more likely to be involved with hazing and less likely to act to prevent it or report it than students in the general student body at this university. Hazing directly negates the positive values taught in the SCM, including collaboration, controversy with civility, citizenship, among others. One possible explanation was that these results underscored the difference between bullying and hazing, where students were less likely to interpret hazing as a form of abuse.

It was also possible that students in the leadership development program have had prior experiences or dispositions that may increase their likelihood of participating in hazing and impeding their likelihood of preventing or reporting hazing. Students entering into the leadership development program studied here were subject to stringent academic, Leadership, and service admission requirements. They frequently graduated high school in the top 5-10\% of their class and were accustomed to a level of excellence beyond that of their peers, including higher retention rates, graduation rates, SAT/ACT scores, college GPAs, and high school GPAs. These students were required to have past leadership experiences; hence these students may have been more motivated to seek opportunities as members of student organizations, fraternities, and sororities, residence hall groups, honors organizations, or student government. It was conceivable that these leadership development students may be 
more tolerant of hazing if they perceived it would help them earn status within student organizations. This related back to the need for a sense of belonging and sense of community students feel in their transition into a new phase of life. This population of leadership development students self-selected to apply for the program and may have different pre-conceived attitudes about hazing, which may be a potential limitation of the study. An important limitation to note is that students in the studied leadership development program chose to apply and become part of the program. Students in this program may also have been exposed to hazing after arriving as first- or second-year students prior to participating in the hazing module. All data was also self-reported and were based on an individual student's understanding of terms and their use. Another limitation may be that the researchers currently work in hazing prevention or leadership education and may have a potential bias towards the results. Delimitations included that the small sample size might not be representative of all college students. Another delimitation was that the sample was all taken from University A, which may not represent other university populations.

Based on this study, it is imperative that campus activities professionals, fraternity and sorority advisors, and leadership educators "meet students where they are" with hazing. Student leaders may need different modes of education regarding hazing prevention and the implications of a hazing culture in a student organization. Student learning goals for student leaders should be tailored differently from the overall campus population. Student leaders need to hear more about the long-term effects of hazing in student organizations and how hazing can affect student leaders individually (i.e., legal and student conduct ramifications). Student leaders are typically high achieving students who look forward to a prosperous academic life and future career. By focusing on how hazing can be disastrous to a student leader's future (even if they were not the ones who were perpetrating the hazing) and how their organization's status as a student organization may suffer, more hazing may be prevented or reported by student leaders.

The first year at college is a unique transitional period. In the college environment, students will establish, test, and refine their new psychological identity. First-year students at a university are transitioning from high school to college. Hence, they may create a new identity for themselves or change their sense of self. New friends may serve a student in a positive manner; however, an identity crisis may occur if a student is having transitional problems, and engaging in risky behavior may be a consequence. (Scheier \& Botvin, 1997). Also, students' development is especially susceptible to societal influences, as noted by Rospenda et al. (2013, pp. 325-326) "The quality of new social interactions at school and in the workplace is important, particularly in terms of the extent to which they may influence developmental trajectories of risky behaviors." Given this, the "trajectories of risky behaviors" in which first-year students participate are thus of particular importance. This suggests a logical basis for expecting that leadership development students could feel increased pressure to conform and fit into established peer expectations and groups, thus exposing and encouraging them to accept hazing behaviors.

Allan and Madden (2008) recommended hazing prevention strategies be designed for broad applicability to students in different student organizations, athletics, and other organizations. Also, it was recommended that prevention efforts be comprehensive research-based programs instead of simply one-time presentations. The online module data suggested more educational programming needed to be developed to clearly demonstrate the dangers, consequences, and undesirability of hazing, as well as present viable alternatives to build cohesion and group dynamics within an organization. This corroborated the recommendations made in the 2014 campus hazing culture site visit report, strengthening policy alignment and enforcement, Leadership and ethical decision-making support and development for students, and hazing prevention messaging from visible campus leaders (Allan, Kerschner, \& Castellano, 2014).

Additionally, a key finding in the 2014 site visit report was of the 423 students who responded to the interviewer's questions about specific behaviors they encountered when attempting to join or maintain membership in an organization, $16.5 \%$ experienced a hazing behavior. This was contrasted with the landmark report developed by Allan and Madden in 2008, which discerned 55\% of all college students experienced at least one hazing behavior. The report on the researched university's campus culture, in light of the data from the AliveTek module, suggested that a new study was needed to examine hazing at the university, as it was likely much higher than the $16.5 \%$ 
originally reported. This is especially relevant given that the student leaders themselves were significantly less likely to report or prevent hazing (as evidenced by the leadership development FTIC students), thus increasing the probability that hazing was occurring on campus.

\section{RECOMMENDATIONS AND CONCLUSION}

\section{Anti-Hazing Module Completion for Student Leaders}

Student leaders could benefit from widespread anti-hazing workshops, online programming, and general information about hazing. Campus activities professionals could oversee these workshops or online programs and possibly require that student leaders in registered student organizations complete an assessment based on the information provided. This assessment could be required annually for student leaders to serve in the upcoming year or for an organization to re-register with the college or university. If new officers are required to learn about hazing, understand ways to prevent hazing, and ascertain alternate methods for building community in their organization, they will benefit. As student leaders did not score as high as the general student population in several areas in this study, student leaders should be targeted to participate in hazing prevention modules.

Another route campus activity professionals can take is to provide incentives to student leaders who complete the training instead of punishments for students who do not complete the training. This may create a positive impression about the training from the student leaders' perspective and encourage compliance in completing the training. It is also important to show the relevance to student leaders for how this training can help the leaders who go through the modules. This training can teach how student leaders can improve their decision-making skills, how to change or modify negative group behavior, conflict resolution skills, and how to successfully onboard new members safely and effectively while also building group unity. Essentially, if student leaders find this training helpful, they will be more likely to complete it.

\section{Anti-Hazing Task Force/National Hazing Prevention Week}

Higher education institutions can establish an anti-hazing task force on campus, including student leaders, campus activities professionals, student conduct officers, fraternity and sorority life professionals, music educators, and athletics/recreational sports personnel. This task force could investigate current rules and regulations at the state and institution level and how this information could be disseminated to student leaders in student organizations. This group could also provide programming for all students about preventing, reporting, and avoiding hazing incidents in student organizations. National Hazing Prevention Week occurs each year in September. This task force could introduce this week of programming to a campus, create a new annual event for students, promote healthy student organization habits, and teach the disadvantages of having a hazing culture in groups. As the findings stated, all new students were required to complete the hazing module. Having a campus-wide week dedicated to hazing prevention would continue students' education as they entered the university.

\section{Institutional Hazing Self-Reporting Clause}

Recommended next steps include the development of self-reporting hazing policies, as well as more comprehensive education about what hazing is, how to identify it, and how to report it to the appropriate campus resources. By developing a better plan to encourage students to report, prevent, and advocate for themselves and others against hazing behaviors, as well as become more involved in leadership education, the safety and security of students will lead to a stronger and healthier campus community. According to the findings, 70.9\% (349/492) of leadership development students were willing to prevent hazing in comparison with $80.2 \%(10,313 / 12,857)$ of university students. Clearly, as seen in figures 8 and 9 , more prevention education is warranted to encourage students to speak up when they see hazing behaviors about to happen in order to prevent harm. Although the university does not have a hazing self-reporting clause in its hazing policy at present, the authors advise that one is established. As seen in figures 6 and 7, 79.0\% (389/492) of leadership development students indicated they would be inclined to report hazing compared with $82.6 \%(10,616 / 12,857)$ of general university students.

The implementation of a hazing self-reporting clause is helpful within an institutional hazing policy with differ- 
ent levels of penalty to protect individuals who report hazing from retaliation, as well as protect organizations if they openly admit to hazing and want to help removing the perpetrators from their organization is paramount to having more students report hazing, and to eradicating hazing on university campuses (Babson College Graduate Student Handbook, 2014; Swick-Duttine, 2011; Wittenberg Hazing Prevention Resources, n.d.). As seen earlier in the results (figures 6 and 7), student leaders were less likely to report hazing. Institutionalizing a self-reporting clause may encourage student leaders to act more ethically in dangerous situations, leading to a stronger and healthier student population. If student leaders were encouraged to report hazing incidents and were a role model to other students, hopefully, the hazing culture may decrease. Likewise, some student leaders (especially those in elected positions) may be more concerned than the general student body with perceptions of their peers. Given this, a social norms approach where assessment data are used to correct a misperceived norm about peer acceptance of hazing behavior may prove promising (Berkowitz, 2010).

After consulting hazing policies at different colleges and within student organizations, the authors have deduced that any policy a university decides to institute must be written with extreme clarity. Students who are considering reporting hazing may be concerned with possible ramifications for students or organizations in reporting, as seen with the reluctance for student leaders to prevent or report hazing behaviors. Hence clear policies need to be outlined by the administration. Hazing is against Florida law, as it is in many states. Although the university can offer protection to an individual or organization's existence at the University, the institutional hazing policy would provide no protections from criminal investigations or litigation (1006.63 Fla. Stat., 2016). This needs to be very clearly worded so that individuals and groups who do come forward understand that any legal ramifications from hazing actions are in no way the university's responsibility. The university cannot offer them any protections from the legal system. As part of the clarity of the policy, it is important to also have different sections for the different levels of protection that the policy can grant. At this time, the authors recommend two sections for levels of protection within the university, as also recommended by Babson College (2014) at individual and organizational levels.

At the broadest level, the reporting individual or organization will have the opportunity to be pardoned within the university, dependent on the hazing behavior(s) reported. If said organization belongs to a larger national or international organization, the institutional hazing policy will not provide them protection from the organization's overarching policies on risk management. There would be a two-week period to self-disclose if hazing is part of an organization's culture and there is help requested for eliminating it. The organization would be required to do an action plan with the Dean of Students office to eradicate hazing. After the two weeks of protected self-disclosure, there would be no deal made or amnesty granted to an organization if they are found to be hazing.

At an individual level, some clarifications need to be made. If an individual chooses to report anonymously, the university cannot assure amnesty and protections because they are unnamed. Only chapter leadership (no parents, new members, etc.) can report and receive protection that is also extended to the organization; in all other cases, the organization is unlikely to be granted any kind of amnesty. Based on research findings, including the student leaders' reluctance to report or prevent hazing, having reporting protections in place may increase the likelihood that students prevent and report hazing behavior.

\section{Creation of a Hazing Prevention Office}

In addition to the development of a policy, creating a dedicated office whose mission is to educate on, prevent, and investigate hazing occurrences on campus is necessary to show the campus community the importance of this type of risky behavior. This new office could serve as a resource for student leaders and all students in organizations with traditionally hazed members. This office should not be housed within Fraternity and Sorority Life, as hazing is a problem that affects other students and those not in fraternity and sorority organizations as well. The authors do not want to undermine the importance of all university personnel responsible for high-risk behaviors. However, similarly to a Title IX investigator, a dedicated individual would allow universities to have a point person in charge of hazing. Title IX and hazing prevention staff members should work together in this work, as they are related to an extent. Although one person would be responsible for hazing prevention efforts, hazing is everyone's responsibility. This aligns with the recommendations by Allan, Kerschner, \& Payne (2018). This location being accessible to all students, not just those in Fraternity and Sorority life, would provide more comprehensive visibility to the issue and 
how hazing is risky behavior that can affect any student. This office creation would also send a strong message to all university faculty, staff, students, and community members that hazing is not tolerated and that the university has an action plan on how to prevent, educate, and investigate all hazing-related matters.

Creating a coalition of trained student advocates to educate their peers about hazing prevention policies, the self-reporting clause, and provide information on how to report if someone is or has been hazed on campus would be instrumental in cultivating a student culture of awareness, and in working to eradicate hazing from campus life. As seen in Table 4, students can learn and grow from strategic educational methods. Continued hazing prevention education and interventions hold the potential to impact campus climate positively by mitigating abusive behavior. A formal group of student advocates for campus hazing prevention could help to ensure that hazing prevention education is available throughout a student's undergraduate years and not just at the beginning of one's college experience (i.e., orientation, a new student module, etc.), creating a positive culture of Leadership and ethical development for all students. Year-round education and interventions are also important because results from the post-test in Table 4 reveal that students who were involved and invested in University A have lower post scores (related to the unacceptability of hazing) than the entering University population who took the survey.

\section{Recommendations for Future Research}

At the very least, there is almost certainly a need to combine the SCM construct with the construct of student attitudes and behaviors related to hazing as described in the literature. The suggestive linkages between hazing prevention and student leadership development theory require further exploration and testing to demonstrate whether the concepts have, in fact, a connection in practice. If, as this study suggests, this is the case, then a dedicated research study with an instrument to measure student attitudes and beliefs relative to both concepts, in terms of a single construct, can be devised such that a significant relationship or non-relationship can be more reliably demonstrated. Also, a further study focusing on student leaders' beliefs and attitudes about hazing before and after different hazing prevention training would further let administrators know which type of training was most beneficial in educating student leaders about the dangers of hazing. By analyzing each training's mode and content, and student leaders' reactions after various workshops, comprehensive and beneficial training can be developed for future use.

In summary, findings from this investigation provided insight about potential alignment and disjuncture between hazing prevention and leadership education on a college campus. More studies are needed to explore these links and add to a growing base of knowledge about hazing prevention. Student leadership education may hold promise for hazing prevention though more remains to be learned. Hazing undermines the missions of postsecondary institutions and can cause harm; thus, its prevention is a university's responsibility. Leadership education for hazing prevention is one promising strategy within a comprehensive approach. Campus-wide policy initiatives, senior leadership commitment and transparency, educational resources, and other research-based prevention strategies are vital ways in which college and university administrators can role model ethical leadership and enhance the health and safety of campus environments. 


\section{REFERENCES}

Allan, E. J., \& DeAngelis, G. (2004). Hazing, masculinity, and collision sports: (Un)becoming heroes. In J. Johnson \& M. Holman (Eds.), Making the team: Inside the world of sport.

Allan, E.J., Kerschner, D. \& Payne, J.M. (2018). College Student Hazing Experiences, Attitudes, and Perceptions: Implications for Prevention. Journal of Student Affairs Research and Practice, 56, 1-17.

Allan, E. J., \& Kinney, M. (2018). Hazing and gender: Lenses for prevention. In H. Nuwer (Ed.), Hazing: Destroying young lives (pp. 100-115). Bloomington, IN: Indiana University Press.

Allan, E. J. \& Madden, M. M. (2008). Hazing in view: College students at risk. Retrieved from http://www.stophazing.org/wp-content/uploads/2014/06/hazing_in_view_web1.pdf.

Allan, E. J., \& Madden, M. (2012). The nature and extent of college student hazing. International Journal of Adolescent Medicine and Health, 24(1), 83-90.

Babson College Graduate Student Handbook. (2014, October 1). Retrieved from: http://www.babson.edu/student-life/communitystandards/Documents/Graduate\%20Handbook.pdf.

Bandura, A. (1991). Social cognitive theory of self-regulation. Organizational Behavior and Human Decision Processes, 50(2), pp. 248-287. https://doi.org/10.1016/0749-5978(91)90022-L

Bandura, A., Barbaranelli, C., Caprara, C. \& Pastorellie, C. (1996). Mechanisms of moral disengagement in exercise of moral agency. Journal of Personality and Social Psychology, 71(2), 364-374.

Bandura, A. (1999). Moral disengagement in the perpetration of inhumanities. Personality and Social Psychology Review, 3(3), pp. 193-209.

Berkowitz, AD (2010) Fostering Health Norms to Prevent Violence and Abuse: The Social Norms Approach. In Kaufman, K (Ed): The Prevention of Sexual Violence: A Practitioner's Sourcebook. NEARI Press.

Buschlen, E. \& Dvorak, R. (2011). The social change model as pedagogy: Examining undergraduate leadership growth. Journal of Leadership Education 10(2), 38-56.

Campo, S., Poulos, G., \& Sipple, J. W. (2005). Prevalence and profiling: Hazing among college students and points of intervention. American Journal of Health Behavior, 29(2), Cornell University: New York. doi: 10.5993/AJHB.29.2.5

Chad Meredith Act, Fla. Penal Code $\$ 1006.63$ et seq, 2005.

Center for Digital Education (2018). Hazing Prevention Course Survey. Retrieved from https://prevent.zone/ hazing-infographic/images/CDE-AliveTek-Hazing-Survey.pdf.

Cimino, A. (2011). The evolution of hazing: Motivational mechanisms and the abuse of newcomers. Journal of Cognition and Culture, 11(3-4), 241-267. doi: 10.1163/156853711X591242.

Einarsen, S., Hoel, H., Zapf, D., \& Cooper, C. L. (2003). The concept of bullying at work. In S. Einarsen (Ed.), Bullying and emotional abuse in the workplace: International perspectives in research and practice (pp. 3-30). Taylor and Francis.

Evans, N. J., Forney, D. S., Guido, F. M., Patton, L. D., \& Renn, K. A. (2009). Student Development in College: Theory, Research, and Practice (2nd ed.). San Francisco, CA: Jossey-Bass.

Finkel, M. (2002). Traumatic injuries caused by hazing practices. American Journal of Emergency Medicine, 20(3), 228-233.

Finley, L. \& Finley, P. (2007). They're just as sadistic as any group of boys! A content analysis of news coverage of sport-related hazing incidents in high schools. Journal of Criminal Justice and Popular Culture, 14(2), 197-219.

Flanagan, C. (2017, November). Death at a Penn State fraternity. The Atlantic. Retrieved from https://www.theatlantic.com/magazine/archive/2017/11/a-death-at-penn-state/540657/.

Haber, P. \& Komives, S. R. (2009). Predicting the individual values of the social change model of leadership development: The role of college students' leadership and involvement experiences. Journal of Leadership Education, 7(3), 133-166. 
Hakkola, L., Allan, E.J., \& Kerschner, D. (2019). Applying utilization-focused evaluation to a high school hazing prevention: A pilot intervention. Evaluation and Program Planning, 75, 61-68.

Hausmann, L. R. M., Schofield, J. W., \& Woods, R. L. (2007). Sense of belonging as a predictor of intentions to persist among African American and White first-year college students. Research in Higher Education, 48(7), 803-839

Higher Education Research Institute. (1996). A social change model of leadership development (Version III). Los Angeles: University of California Los Angeles, Higher Education Research Institute.

Hoel, H., Glaso, L., Hetland, J., Cooper, C.L., \& Einarsen, S. (2010). Leadership styles as predictors of self-reported and observed workplace bullying. British Journal of Management, 21, 453-468.

Hoover, N. (1999). National survey: Initiation rites and athletics for NCAA sports teams. Retrieved from http:// www.alfred.edu/sports_hazing/docs/hazing.pdf.

Hoover, N., \& Pollard, N. (2000). Initiation rites in American high schools: A national survey. Alfred, NY: Alfred University.

Johnson, J. (2011). Through the liminal: A comparative analysis of communitas and rites of passage in sport hazing and initiations. Canadian Journal of Sociology, 36(3), 199-227.

Johnson, J., \& Holman, M. (Eds.) (2004). Making the team: Inside the world of sports initiations and hazing. Toronto, CA: Canadian Scholars' Press Inc.

Jones, R. L. (2004). Black haze: Violence, sacrifice, and manhood in Black Greek-letter fraternities. Albany: State University of New York Press.

Keating, C.F., Pomerantz, J., Pommer, S.D., Ritt, S., Miller, L.M., \& McCormick, J. (2005). Going to college and unpacking hazing: A functional approach to decrypting initiation practices among undergraduates. Group Dynamics: Theory, Research, and Practice, 9(2),104-126.

King, P. \& Mayhew, M. (2002). Moral judgment development in higher education: Insights from the Defining Issues Test. Journal of Moral Education, 31 (3), 247-270.

Kirby, S., \& Wintrup, G. (2002). Running the gauntlet: An examination of initiation/hazing and sexual abuse in sport. Journal of Sexual Aggression: An International, Interdisciplinary Forum for Research, Theory and Practice, 8(2), 49-68.

Kohlberg, L. (1976). Moral stages and moralization: The cognitive-developmental approach. In T. Lickona (Ed.), Moral development and behavior: Theory, research, and social issues (pp.31-53). Holt, Rinehart and Winston.

Komives, S. R. \& Wagner, W. (2012). Leadership for a better world: Understanding the social change model of leadership development. San Francisco: Jossey-Bass.

Kuh, G. D. (2008). High-impact educational practices: What are they, who has access to them, and why they matter. Washington, DC: Association of American Colleges and Universities.

Leadership development program. (n.d.). Retrieved 2017, from http://leadershipdevelopment program.sdes. universityA.edu/.

Massey, K.D. \& Massey, J. (2017) It Happens, Just Not to Me: Hazing on a Canadian University Campus. Journal of College and Character, 18(1), 46-63.

McMillan, D. W., \& Chavis, D. M. (1986). Sense of community: A definition and theory. Journal of Community Psychology, 14(1), 6-23.

Nuwer, H. (1999). Wrongs of passage: Fraternities, sororities, hazing, and binge drinking. Indiana University Press.

Owen, S. S., Burke, T. W., \& Vichesky, D. (2008). Hazing in student organizations: Prevalence, attitudes, and solutions. Oracle: The Research Journal of the Association of Fraternity/Sorority Advisors, 3(1), 40-58.

Parks, G. S. \& Laybourn, W. M. (2017). Asian American fraternity hazing: An analysis of community-level factors. Asian Pacific American Law Journal, 22(1), 29-56.

Parks, G. S., Jones, S. E., Ray, R., Hughey, M. W., \& Cox, J. M. (2015). White boys drink, black girls yell: A racialized and gendered analysis of violent hazing and the law. Journal of Gender, Race \& Justice, 18, 93-158. 
Pascarella, E. T., \& Terenzini, P. T. (2005). How college affects students (Vol. 2). K. A. Feldman (Ed.). San Francisco, CA: Jossey-Bass.

Rogers, S., Rogers, C., \& Anderson, T. (2012). Examining the link between pledging, hazing, and organizational commitment among members of a black greek fraternity. Oracle: The Research Journal of the Association of Fraternity/Sorority Advisors, 7(1), 43-53.

Rospenda, K., Richman, J., Wolff, J., \& Burke, L. (2013). Bullying victimization among college students: Negative consequences for alcohol use. Journal of Addictive Diseases, 32(4), 325-342.

Samnani, A. \& Singh, P. (2012). 20 Years of workplace bullying research: A review of the antecedents and consequences of bullying in the workplace. Aggression and Violent Behavior, 17(6). 581-589.

Scheier, L. M., \& Botvin, G. J. (1997). Expectancies as mediators of the effects of social influences and alcohol knowledge on adolescent alcohol use: A prospective analysis. Psychology of Addictive Behaviors, 11(1), 48-64. doi:10.1037/0893-164X.11.1.48.

Silveira, J. M. \& Hudson, M. W. (2015). Hazing in the college marching band. Journal of Research in Music Education, 63(1), 5-27.

Swick-Duttine, A. (2011, May 10). SUNY Plattsburgh Creates Policy on Hazing Amnesty. Retrieved from http:// www.sigepblog.org/2011/05/suny-plattsburgh-creates-policy-on.html.

University of Alabama Code of Student Conduct. (2016, August). Retrieved from: http://www.sc.ua.edu/conduct.pdf.

University A: Hazing Survey Report (2014, July). Hazing Culture Assessment Report: University A. University A Board of Trustees. (2016). UNIVERSITY A Collective Impact Strategic Plan. 26 March 2016. Retrieved from: http://www.University A.edu/wpcontent/uploads/2012/08/UNIVERSITY A-Strategic-Plan-BOT-FINAL052616-Web.pdf.

University A The Golden Rule 2016-2017 Student Handbook. 2016. Retrieved From: http://goldenrule.sdes. University A.edu/docs/goldenrule.pdf.

University of Pittsburgh at Bradford Student Code of Conduct. (2016, August). Retrieved from http://www.upb. pitt.edu/studenthandbook.pdf.

Van Raalte, J., Cornelius, A., Linder, D., \& Brewer, B. (2007). The relationship between hazing and team cohesion. Journal of Sports Behavior, 30, 491-507.

Veliz-Calderon, D., \& Allan, E. J. (2017). Defining hazing: Gender differences. Oracle: The Research Journal of the Association of Fraternity/Sorority Advisors, 12(2), 12-25.

Wikipedia contributors. (2018, September 24). Lawrence Kohlberg's stages of moral development. In Wikipedia, The Free Encyclopedia. Retrieved from: https://en.wikipedia.org/w/index.php?title=Lawrence_Kohlberg\%27s stages_of_moral development\&oldid=861080082

Wittenberg Hazing Prevention Resources. (n.d.). Retrieved February 22, 2017, from http://www.wittenberg.edu/ administration/studentconduct/hazing/policy 